\title{
Experimental characterization of plasma start-up using ECRH in preparation of W7-X operation
}

\author{
M. Preynas ${ }^{1}$, D. Aßmus ${ }^{1}$, H. Igami ${ }^{3}$, S. Kado ${ }^{2}$, S. Kobayashi ${ }^{2}$, S. Kubo ${ }^{3}$, H.P. Laqua ${ }^{1}$, T. Mutoh ${ }^{3}$, K. Nagasaki ${ }^{2}$, \\ M. Otte ${ }^{1}$, T. Shimozuma ${ }^{3}$, T. Stange ${ }^{1}$ and Y. Yoshimura ${ }^{3}$ \\ ${ }^{1}$ Max-Planck-Institut für Plasmaphysik (IPP), D-17491 Greifswald, Germany \\ ${ }^{2}$ Institute of Advanced Energy, Kyoto University, Gokasho, Uji, Kyoto 611-0011, Japan \\ ${ }^{3}$ National Institute for Fusion Science, 322-6 Oroshi-Cho, Toki-City, Gifu 509-5292, Japan
}

\begin{abstract}
The upcoming operation of Wendelstein 7-X (W7-X) will be supported by an Electron Cyclotron Resonance Heating (ECRH) system working at $140 \mathrm{GHz}$ in second harmonic at the nominal magnetic field of 2.5T. Because the optimization of the plasma breakdown is crucial to ensure a successful plasma build-up, dedicated plasma start-up experiments were performed on three stellarator/heliotron devices: Heliotron J, LHD and WEGA. Start-up behavior and dependencies on ECRH injected power, neutral gas pressure and rotational transform were obtained in X2 heating. Plasma start-up delay time decreases with the increase in ECRH input power. However, this behavior saturates when low pre-fill neutral gas pressure conditions are met. Both the delay time and the electron density are an increasing function of the gas pressure. On Heliotron J and WEGA devices, the higher the rotational transform is, the faster the start-up and the higher the plasma density are. Analysis of the temporal evolution of the plasma start-up shows that plasma start-up on stellarators is a twostep process. In addition, off-axis heating experiments are characterized by a longer plasma start-up duration compared to on-axis heating discharges. Third harmonic in X-mode has been attempted on LHD for different neutral gas puffing settings but no plasma breakdown was achieved. This multi-machine study was useful to define ECRH start-up scenarios for W7-X.
\end{abstract}

\section{Introduction}

The construction of the Wendelstein 7-X (W7-X) basic machine is completed (figure 1) and the commissioning phase of the device has started in April 2014. Electron Cyclotron Resonance Heating (ECRH) being the sole heating system available during the first experimental campaign of W7-X [1], a successful start-up of the plasma using ECRH has to be insured. Contrary to tokamaks, stellarator/heliotron devices have the main advantage to have the nested magnetic flux surfaces before plasma breakdown. W7-X will not have to face the plasma current build-up issue. Nevertheless, plasma startup conditions have to be optimized in order to avoid, or at least, minimize damages caused by microwave stray radiation. Indeed, during low density and low temperature plasma conditions of plasma start-up phase, stray radiation induced by non-absorbed ECRH power is an important machine safety issue. In order to prepare plasma start-up scenarios for the upcoming operation phase of W7-X, a multi-machine study was conducted through dedicated plasma start-up experiments. The parametric study performed on Heliotron J [2], LHD [3] and WEGA [4] devices allows an extrapolation to W7-X. The relevant machine characteristics regarding plasma start-up are presented in section 2 . In section 3, the characterization of time evolution of the plasma start-up for different magnetic configurations highlights a twophase process. Section 4 gives the characteristics of the plasma start-up regarding the ECRH power and the prefill neutral gas pressure. Before the conclusion given in section 6 , section 5 presents an extrapolation of the experimental results to a plasma start-up scenario for the first experimental campaign of W7-X. 

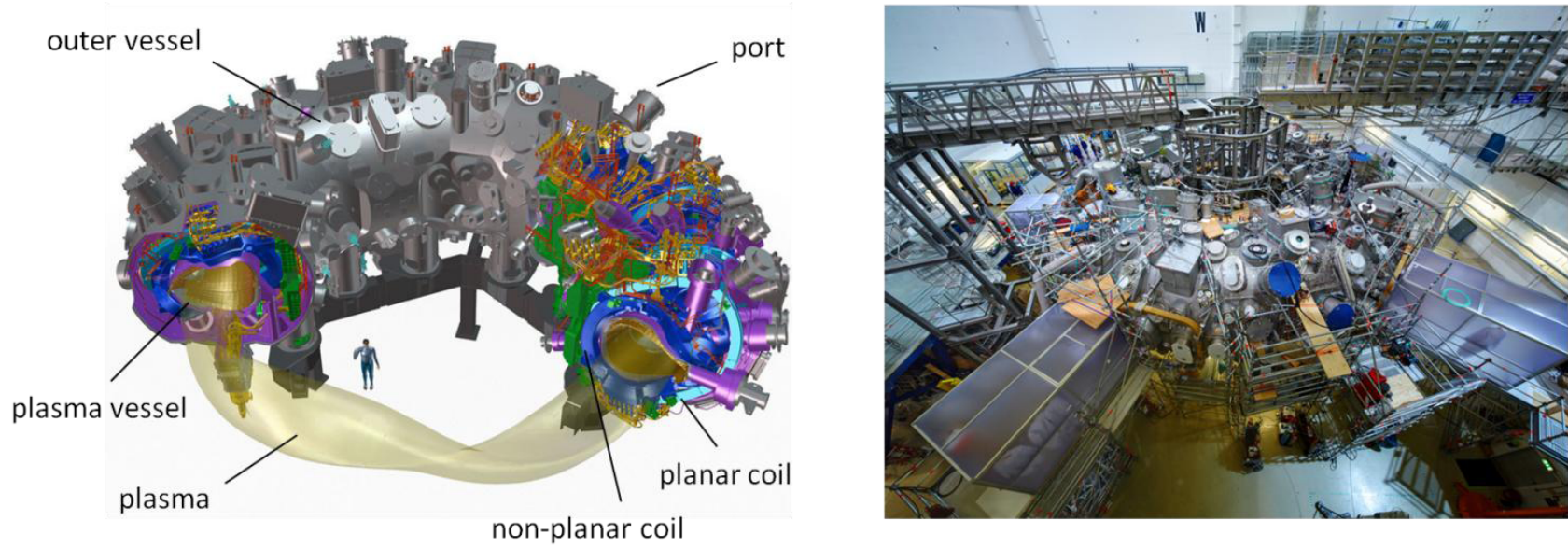

Figure 1. Left: sketch of W7-X. Right: view into the experimentation hall at the end of 2013: the basic machine is completed.

\section{Plasma start-up experiment settings}

The operation of W7-X will be supported by an ECRH system working at $140 \mathrm{GHz}$ at the nominal magnetic field of $2.5 \mathrm{~T}$. During the first experimental campaign, the power will be generated by 6 gyrotrons with about $900 \mathrm{~kW}$ of microwave power each for $30 \mathrm{~min}$. Beyond the standard start-up scenario of on-axis heating in X2, offaxis heating and $3^{\text {rd }}$ harmonic are also considered for plasma operation at lower magnetic field to get a further operation point for W7-X.

Previous experimental studies related to plasma startup using ECRH at the second harmonic have been already conducted. In particular, experiments in Heliotron J [5], TJ-II [6] and CHS [7] devices show a minimum delay time of plasma start-up for a pure Xmode polarization. Furthermore, in X2-mode, the delay time increases with the increase in $\mathrm{N}_{/ /}$during Heliotron $\mathrm{J}$ [8] and TJ-II [9] experiments. Table 1 gives important device parameters for plasma start-up considerations of Heliotron J, LHD and WEGA, such as plasma volume, magnetic field amplitude and the ECRH frequency used for plasma start-up. In order to complete previous studies [2], the influence of a scan in rotational transform and off-axis heating on the plasma parameters have been studied on WEGA and Heliotron J, as mentioned in table 1. A wide range of ECRH power and pre-fill neutral gas pressure has also been investigated on the three devices.

\section{Characterization of 3D effects}

\subsection{Video characterization}

In this paragraph, the temporal description of the plasma start-up is based on a discharge performed on Heliotron $\mathrm{J}$ in on-axis heating and X2 mode. This discharge is illustrated in figure 2 by three images taken by a fast CCD camera, and the temporal evolution of ECRH power, electron density and $\mathrm{H}_{\alpha}$ intensity.

A temporal evolution analysis led to the separation of the plasma start-up in two main phases. The first one is characterized by a thin ring of plasma, which is created around the magnetic axis where the resonance condition for ECRH absorption is fulfilled, and having a radial size of the order of the ECRH beam waist (see picture number 1 in figure 2). First signals in all the poloidally

Table 1. Range of parameters investigated during the start-up experiments performed on WEGA, Heliotron J and LHD. Parameters of $\mathrm{W} 7-\mathrm{X}$ are given for the sake of comparison and further extrapolation.

\begin{tabular}{|c|c|c|c|c|}
\hline & WEGA & Heliotron J & LHD & W7-X \\
\hline $\mathbf{V}_{\text {PLASMA }}\left[\mathbf{m}^{3}\right]$ & 0.14 & {$[0.68-0.90]$} & 27.7 & 30 \\
\hline $\mathbf{B}[\mathbf{T}]$ & 0.5 & 1.25 & 1.375 & 2.5 \\
\hline $\mathbf{f}[\mathbf{G H z}]$ & 28 & 70 & 77 & 140 \\
\hline $\mathbf{t} / \mathbf{2} \boldsymbol{I I}$ & {$[0.02-0.3]$} & {$[0.48-0.64]$} & 0.6 & 0.9 \\
\hline heating & On- \& off-axis & On- \& off-axis & On-axis & On- \& off-axis \\
\hline $\mathbf{P}_{\text {ECRH }}[\mathbf{k W}]$ & {$[3-9]$} & {$[160-240]$} & {$[500-2100]$} & $\leq 5000$ \\
\hline $\mathbf{P}_{\text {neutral }}[\mathbf{P a}]$ & {$\left[5.4 \cdot 10^{-4}-2.5 \cdot 10^{-2}\right]$} & {$\left[1.6 \cdot 10^{-5}-2.4 \cdot 10^{-3}\right]$} & {$\left[7 \cdot 10^{-4}-1 \cdot 10^{-3}\right]$} & {$\left[1 \cdot 10^{-4}-1 \cdot 10^{-3}\right]$} \\
\hline
\end{tabular}



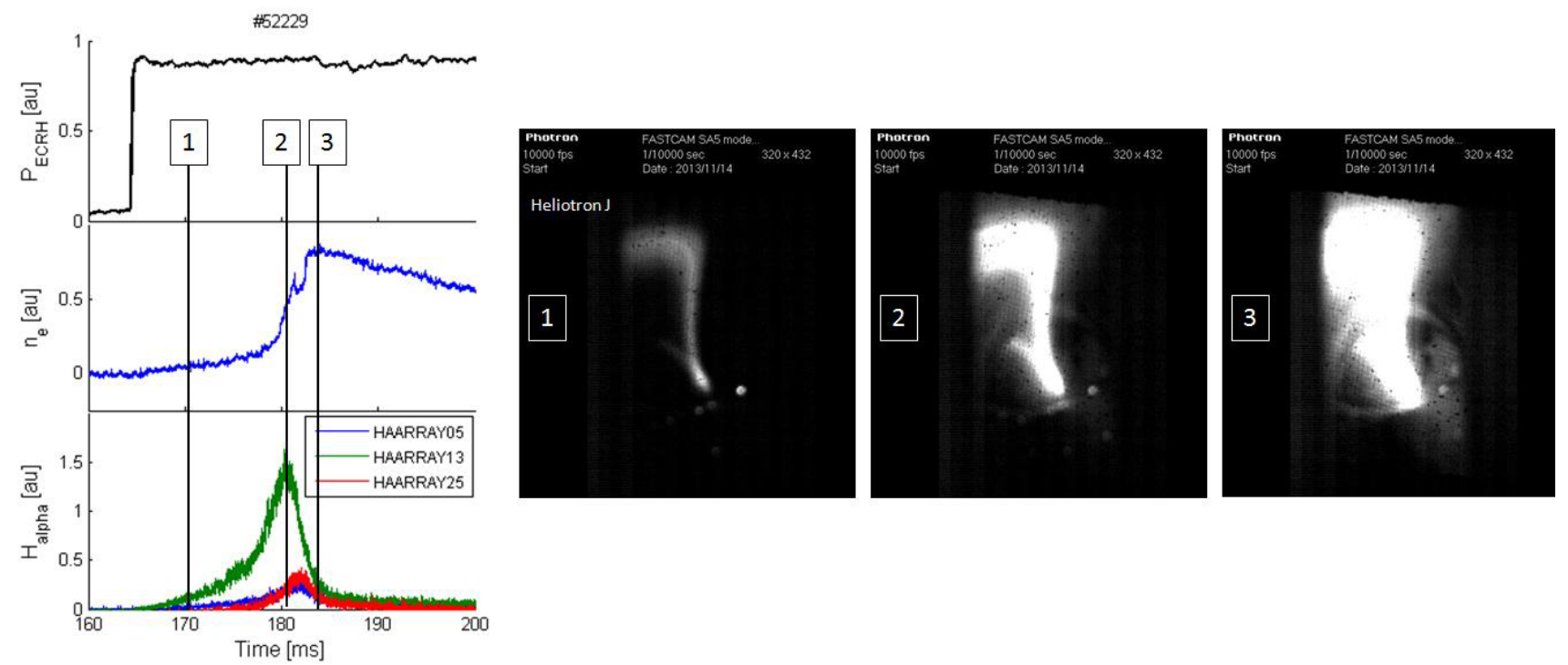

Figure 2. Left: fast CCD images $\left(10^{4} \mathrm{fps}\right)$ from the plasma start-up sequence of on-axis heating discharge in X2-mode in Heliotron J. Right: corresponding temporal evolution of ECRH power, electron density (interferometer) and signal of three $\mathrm{H}_{\alpha}$ channels (one center channel (05) and two edge channels (13 \& 25)).

distributed lines of $\mathrm{H}_{\alpha}$ measurements attest the occurrence of ionization process throughout the confined region. This provides the evidence of plasma expansion that initiates the plasma build-up phase (number 2 in figure 2). Once the ECRH absorption has significantly increased to overcome the losses (radiation, recombination, electron cooling rate) and to get high ionization probability, plasma density build-up occurs. The transition between the two phases is characterized by the change in the slope of the electron density signal. The end of plasma build-up phase corresponds to the maximum in density and the strong $\mathrm{H}_{\alpha}$ signal decrease (number 3 in figure 2). Heliotron $\mathrm{J}$ experiments confirm the two-phase process of plasma start-up already characterized on WEGA [10].

\subsection{Off-axis versus on-axis heating}

In order to characterize the impact of the magnetic configuration on the plasma start-up, electron cyclotron resonance position was scanned during WEGA experiments. Three different configurations were studied, on-axis heating (blue curves), off-axis (green curves) and far off-axis (red curves) heating with a resonance shifted respectively to r/a equals to $0,0.30$ and 0.65 on the high field side. In figure 3 (left side) the time evolution of the ECRH power and electron density measured by the interferometer is plotted. In this figure, the delay in the plasma density build-up is clearly enhanced from on-axis heating to far-off axis heating discharge. Pictures from the first phase of plasma start-up are shown in figure 2 (right side) for each configuration. The pink circular arc represents the magnetic axis and the dashed yellow vertical line the resonance position. Ionization occurs mainly on the magnetic surface crossing the electron cyclotron resonance layer. In the case of on-axis heating, resonance takes place at the intersection of the ECRH beam with the magnetic axis, defining a thin ring of plasma around the torus having the size of the ECRH beam $(13 \mathrm{~mm})$. In off-axis heating configuration, the resonance is significantly shifted from the magnetic axis, to a distance superior to the ECRH beam waist. Trajectory of accelerated electrons is mainly located on the magnetic surfaces crossing the resonance layer. Thus, the volume of plasma to ionize and to heat sufficiently in order to overcome the losses is much larger in off-axis heating than in the on-axis heating case. For the same input power, off-axis heating leads to a longer plasma start-up and a decrease in ionization degree at high pressure conditions and/or at limited ECRH input power.

\subsection{Rotational transform dependence}

In addition to the comparison between on- and off-axis heating, the effect of the rotational transform on plasma start-up performance was investigated during Heliotron $\mathrm{J}$ and WEGA experiments. On these machines, rotational transform was varied, from $1 / 2 \Pi$ equals 0.48 to 0.64 in hydrogen plasma in Heliotron $J$, and from $1 / 2 \Pi$ equals 0.02 to 0.21 in helium plasma in WEGA. All these discharges were performed with on-axis heating. In figure 4 , the delay time is plotted as a function of gas pressure for different values of rotational transform. The figure on the left side (resp. right side) corresponds to Heliotron J (resp. WEGA) discharges. On both devices, plasma start-up is delayed up to a factor of 3 when the rotational transform is varied. Moreover, dependence on iota is an increasing function of gas pressure. 

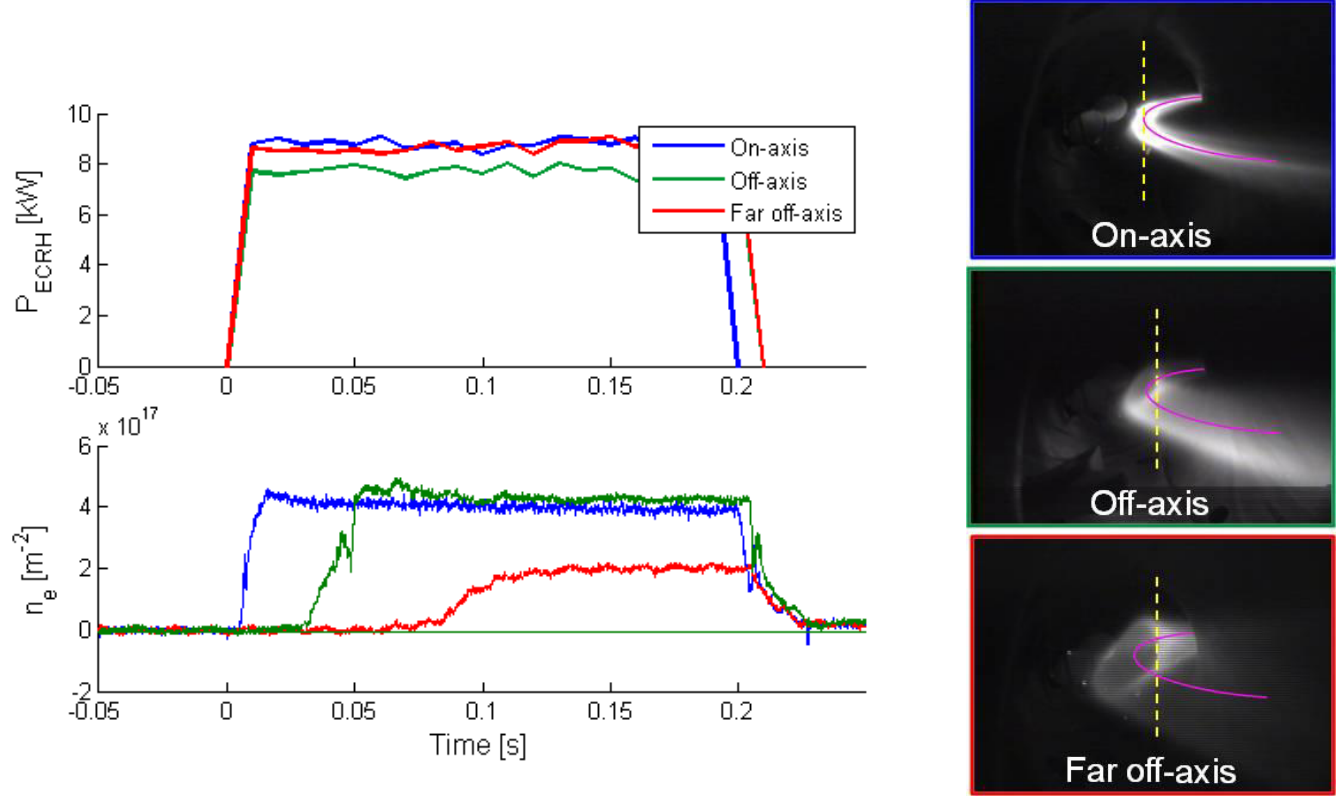

Figure 3. Comparison of on-, off- and far off-axis heating discharges performed in WEGA in helium. Except EC resonance position, all other parameters are comparable. Left: temporal evolution of ECRH power and electron density. Right: video images of the breakdown phase of the discharge.
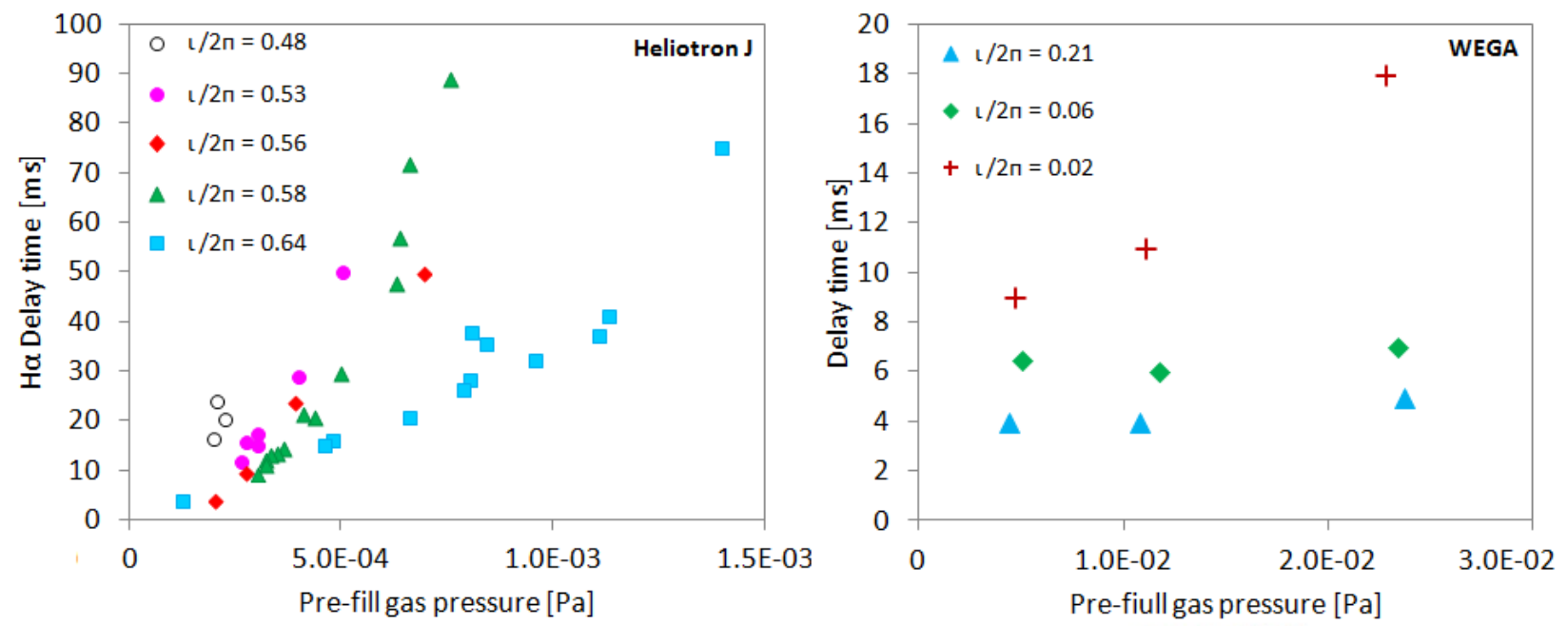

Figure 4. $\mathrm{H}_{\alpha}$ delay time as a function of pre-fill neutral gas pressure of Heliotron $\mathrm{J}$ (left) and WEGA (right) discharges performed at different rotational transform values.

\section{ECRH power and pre-fill neutral gas pressure dependences}

\subsection{X2-heating}

Experimental results from Heliotron J and LHD presented in this paragraph are characterizing the ECRH power and pre-fill neutral gas pressure dependences. For both machines, no additional gas puffing was conducted during the ECRH pulse in order not to interfere with the plasma start-up behavior.

Discharges from Heliotron J performed at three different ECRH power levels ranging from $160 \mathrm{~kW}$ to $240 \mathrm{~kW}$ are presented. In figure 5 , the $\mathrm{H}_{\alpha}$ delay time is plotted, which is defined by the duration between the switch-on of the ECRH power and reaching the peak of the central channel of $\mathrm{H}_{\alpha}$ measurement, as a function of the pre-fill gas pressure. Independent of the level of ECRH power, $\mathrm{H}_{\alpha}$ delay time is an increasing function of the neutral gas pressure, but is even longer as the power is lower. Successful plasma start-up experiences an upper limit regarding the pressure, but this pressure limit can be increased by more input power. Indeed, by increasing ECRH power from $160 \mathrm{~kW}$ to $240 \mathrm{~kW}$, plasma start-up can be achieved at pressure two times higher. Moreover, increasing the power enables a decrease in $\mathrm{H}_{\alpha}$ delay time, except for the discharges performed in a low pressure range (below $1 \cdot 10^{-4} \mathrm{~Pa}$ ). Reducing the pressure leads to a shorter delay time but this behavior saturates. $\mathrm{H}_{\alpha}$ delay time cannot be reduced below $3 \mathrm{~ms}$ because in this low pressure condition, density is too low for a sufficient ECRH power absorption that allows a plasma build-up. 

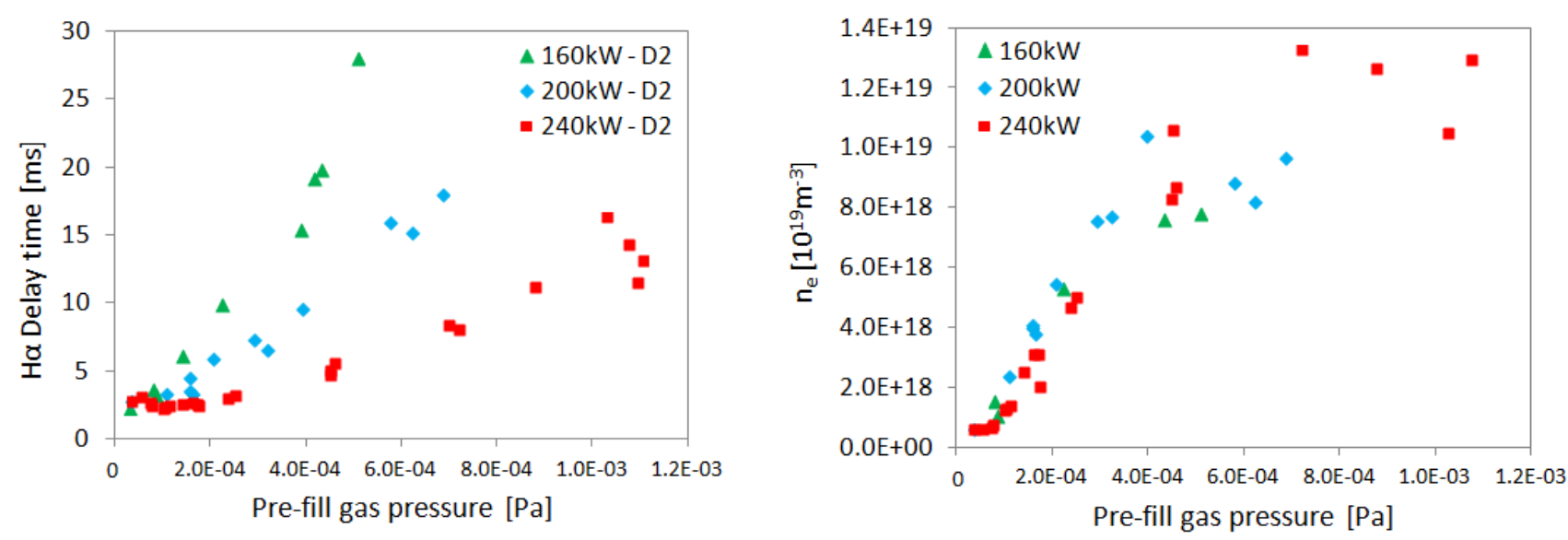

Figure 5. Left: $\mathrm{H}_{\alpha}$ delay time versus pre-fill neutral gas pressure of three series of Heliotron $\mathrm{J}$ discharges performed at different levels of ECRH power. Right: electron density measured at the end of plasma build-up of discharges plotted on the left side.

In order to complete the study, a wide scan was realized in LHD for two different pre-fill neutral gas pressures $\left(7 \cdot 10^{-4}\right.$ and $\left.1 \cdot 10^{-3} \mathrm{~Pa}\right)$. The $\mathrm{H}_{\alpha}$ delay time as a function of ECRH power is plotted in figure $6 . \mathrm{H}_{\alpha}$ delay time of the high pressure series discharges shows a stronger dependence in ECRH power than the low pressure series discharges, which is in agreement with both Heliotron $\mathrm{J}$ (figure 5) and WEGA results [10]. An important characteristic to point out for the W7-X operation is the saturation in the decrease in the delay time with the increase in the ECRH power observed at low pressure. Thus, from a machine safety point of view, it is of vital importance to first find the optimal operating conditions of pressure before increasing ECRH input power.

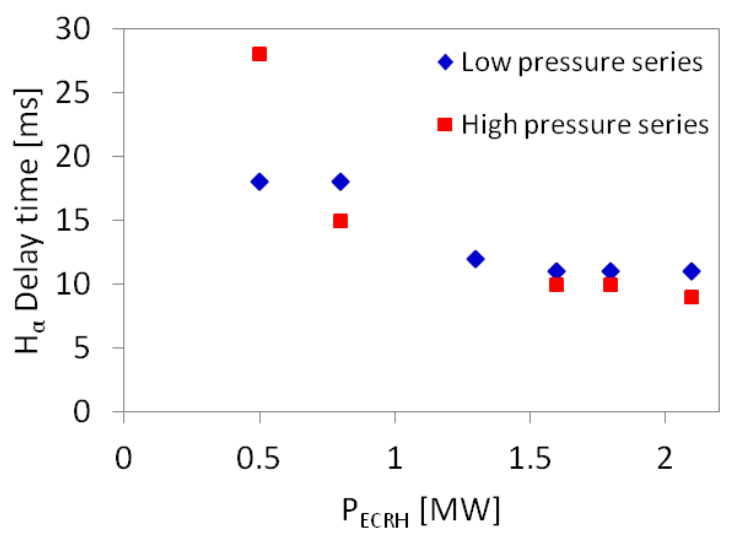

Figure 6. $\mathrm{H}_{\alpha}$ delay time versus ECRH power for two series of discharges performed on LHD at two different pre-fill gas pressure levels: $7 \cdot 10^{-4}$ and $1 \cdot 10^{-3} \mathrm{~Pa}$.

\subsection{X3-heating attempts in LHD}

Plasma start-up using X3 heating was attempted in LHD because of the motivation for $\mathrm{W} 7-\mathrm{X}$ to have a plasma start-up scenario at low magnetic field, $1.67 \mathrm{~T}$ instead of the nominal value of $2.5 \mathrm{~T}$. The reference discharge \#120482 was repeated by changing only the pre-fill gas pressure setting. Its time evolution of ECRH power, electron density and $\mathrm{H}_{\alpha}$ measurements is plotted in figure 7. Up to $3.2 \mathrm{MW}$ of ECRH power were launched into the vessel using three $77 \mathrm{GHz}$ gyrotrons. A series of five discharges over a wide range of pressure $\left[1.6 \cdot 10^{-5}\right.$ $3.35 \cdot 10^{-3}$ ] was performed, but no plasma breakdown occurred as during the reference failed discharge \#120482. Thus, pre-ionization by non-resonant heating using $2.45 \mathrm{GHz}$ magnetron or NBI heating is required for plasma start-up with X3.
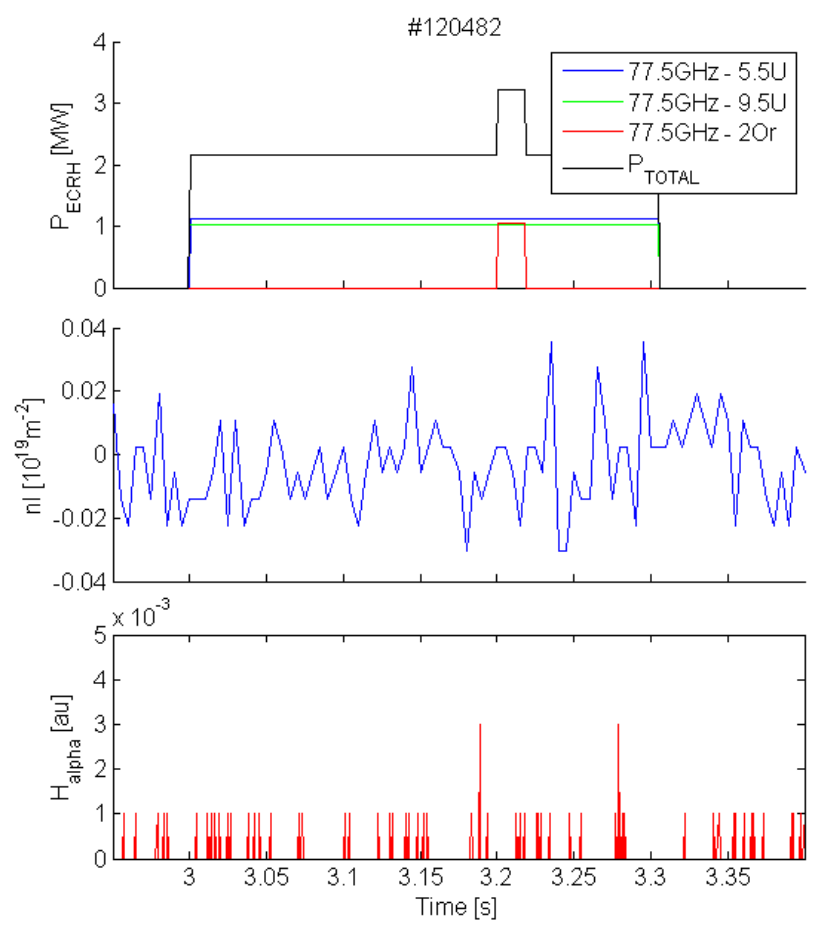

Figure 7. Time evolution of ECRH power, electron density and $\mathrm{H}_{\alpha}$ measurements of the \#LHD120482 discharge performed using X3 only. 


\section{Discussions - Extrapolation to W7-X}

Beyond the success of the plasma start-up, the overall machine safety has to be insured. The main issue is the stray radiation induced by the non-absorbed ECRH power especially during the plasma start-up. However, as observed during experiments, minimizing the delay time of the plasma start-up is synonym of a low plasma density and thus high risk of failure in plasma build-up due to a too low ECRH absorption efficiency. In such operational regimes, high stray radiation level is expected. Furthermore, an increase of the ECRH input power, if pressure is high enough, leads to a decrease in the plasma start-up time. In that case, plasma density performance increases only if fully ionization is not reached for lower power.

Range of plasma start-up delay time of robust discharges performed on Heliotron J, LHD and WEGA is in the order of a few ten milliseconds, which is quite short regarding the ECRH stray radiation issue. This result is promising for $\mathrm{W} 7-\mathrm{X}$ operation.

Based on the multi-machine study, an optimal scenario of plasma start-up regarding the ECRH power settings was defined for W7-X operation. For a reliable and robust plasma start-up, the application of the ECRH power in two steps is suggested, as represented in figure 8 . A short pulse $(100 \mathrm{~ms})$ of several megawatts of ECRH power in on-axis heating should promptly breakdown the plasma in the higher confined region around the magnetic axis. Then in the second phase of the discharge, half the level of power using both on- and offaxis heating, using two beams for an efficient plasma build-up, is considered.

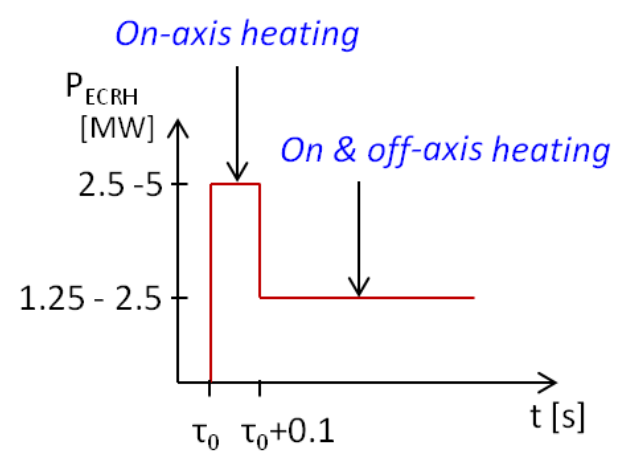

Figure 8. Sketch of plasma start-up scenario for W7-X regarding the ECRH power settings.

\section{Conclusions}

The characterization of plasma start-up through dedicated experiments performed on Heliotron J, LHD and WEGA devices gives high confidence in the plasma start-up during the first operation phase of W7-X. Start-up behavior and dependencies on ECRH injected power, neutral gas pressure and rotational transform were obtained in X2 heating. Robust plasma start-up were performed on a wide range of pre-fill gas pressure, ECRH power and rotational transform with a short delay time of the order of a few ten milliseconds. Experimental results show that the pre-fill neutral gas pressure is the main parameter to control and optimize to reach a successful plasma start-up. However, ECRH input energy can be temporally optimized in order to obtain a prompt plasma breakdown followed by a successful plasma build-up. Nevertheless, unsuccessful plasma start-up attempts in X3 heating in LHD does not give confidence for such scenario at lower magnetic field in $\mathrm{W} 7-\mathrm{X}$, since no heating system for a pre-ionization to assist $\mathrm{X} 3$ heating will be available during the first experimental campaign of W7-X.

\section{Acknowledgements}

This project has received funding from the Euratom research and training programme 2014-2018.

This work is performed with the support and under the auspices of the Collaboration Programme of the NIFS Collaborative Research Programme (NIFS10KUHL030), the NIFS/NINS project of Formation of International Scientific Base and Network.

\section{References}

1. V. Erckmann et al., AIP Conf. Proc. 1580, 542 (2014), http://dx.doi.org/10.1063/1.4864608

2. K. Nagasaki et al., JKPS 49 (2006) S18 S24.

3. H. Igami, $18^{\text {th }} E C E$-ECRH conference, Nara, Japan, 22-25 April 2014

4. M. Otte et al., Proc. 17th International Stellarator and Heliotron Workshop, Princeton, 12-16 October 2009 (2009).

5. K. Nagasaki et al., Nucl. Fusion 45, 13 (2005)

6. A. Cappa et al., $32^{\text {nd }}$ EPS Conf., Tarragona (2005)

7. Y. Yoshimura et al., J. Plasma Fus. Res. 6 (2004)

8. Bo Lu, PFR 7, 1202153 (2012)

9. J. Stober, Nucl. Fusion 51083031 (2011)

10. M. Preynas et al., AIP Conf. Proc. 1580, 498 (2014) http://dx.doi.org/10.1063/1.4864597

11. A. Cappa et al., Nucl. Fusion 41, 363 (2001), http://iopscience.iop.org/0029-5515/41/4/302 